\title{
Empagliflozin protects against atherosclerosis progression by modulating lipid profiles and sympathetic activity
}

\author{
Yihai $\mathrm{Liu}^{1 \dagger}$, Jiamin $\mathrm{Xu}^{2 \dagger}$, Mingyue $\mathrm{Wu}^{2 \dagger}$, Biao $\mathrm{Xu}^{1,2^{*}}$ and Lina Kang ${ }^{1,2^{*}}$
}

\begin{abstract}
Background: Several large clinical trials have confirmed the cardioprotective role of sodium-glucose cotransporter 2 inhibitors (SGLT2i) in patients with type 2 diabetes. However, whether empagliflozin, as an SGLT2i, could alleviate atherosclerosis progression in non-diabetic states remain unknown.

Methods: ApoE-/- mice were fed a Western diet for 12 weeks to induce atherosclerosis. On the 7th week, a group of mice were treated with drinking water containing empagliflozin $(10 \mathrm{mg} / \mathrm{kg} /$ day), while another group was given normal water. At the 12th week, the whole aortas of each group were harvested. Oil Red O, HE and Movat staining were performed for atherosclerotic lesion area and size. Mouse serum lipid profiles (total cholesterol [TC],

triglyceride $[T G]$, low-density lipoprotein-c [LDL], and high-density lipoprotein-c [HDL]), systemic inflammation levels (IL-1 $\beta, I L-6$ and IL-10), renin-angiotensin-aldosterone system (RAAS) components and sympathetic activity (norepinephrine and neuropeptide $Y$ ) indicators were measured by ELISA.

Results: Empagliflozin reduced the atherosclerotic lesion burden $(-8.6 \%, P=0.004)$ at aortic root in ApoE-/- mice. In addition, empagliflozin decreased body weight $(-3.27 \mathrm{~g}, P=0.002$ ), lipid profiles (TC: $[-15.3 \mathrm{mmol} / \mathrm{L}, P=0.011]$; TG: $[-2.4 \mathrm{mmol} / \mathrm{L}, P<0.001] ; \mathrm{LDL}:[-2.9 \mathrm{mmol} / \mathrm{L}, P=0.010]$ ), RAAS (renin [-9.3 ng/L, $P=0.047] ;$ aldosterone $[-16.7 \mathrm{ng} / \mathrm{L}, P<$ $0.001]$ ) and sympathetic activity (norepinephrine [-8.9 ng/L, $P=0.019]$; neuropeptide $Y[-8.8 \mathrm{ng} / \mathrm{L}, P=0.002]$ ). However, the anti-inflammatory effect of empagliflozin was not significantly evident.

Conclusions: The early atherosclerotic lesion size was less visible in empagliflozin-treated mice. Empagliflozin could decrease lipid profiles and sympathetic activity in atherosclerosis.
\end{abstract}

Keywords: Atherosclerosis, Sodium-glucose cotransporter 2 inhibitor, Empagliflozin, Sympathetic activity, Reninangiotensin-aldosterone system

\section{Background}

Sodium-glucose cotransporter 2 (SGLT2) is mainly distributed in the proximal tubule of the kidney and is responsible for reabsorption of $80 \%-90 \%$ of glucose load [1]. SGLT2 inhibitors (SGLT2i) can reduce glucose reabsorption in the proximal tubules and increase urine

\footnotetext{
*Correspondence: xubiao62@nju.edu.cn; kanglina@njglyy.com

'Department of Cardiology, Nanjing Drum Tower Hospital, Clinical College of Nanjing Medical University, Jiangsu 210008 Nanjing, China

Full list of author information is available at the end of the article
}

glucose excretion with high selectivity and specificity, thereby reducing blood glucose levels [2]. With the loss of glucose in the urine, body weight and blood pressure also decrease significantly [3].

Recent clinical studies have shown that SGLT2i can reduce cardiovascular mortality and heart failure hospitalization rates in patients with type 2 diabetes [4-6], making them the first hypoglycemic agents to reduce cardiovascular adverse events independent of glycemic control [7]. Some studies revealed that

C C The Author(s). 2021 Open Access This article is licensed under a Creative Commons Attribution 4.0 International License, which permits use, sharing, adaptation, distribution and reproduction in any medium or format, as long as you give appropriate credit to the original author(s) and the source, provide a link to the Creative Commons licence, and indicate if changes were made. The images or other third party material in this article are included in the article's Creative Commons licence, unless indicated otherwise in a credit line to the material. If material is not included in the article's Creative Commons licence and your intended use is not permitted by statutory regulation or exceeds the permitted use, you will need to obtain permission directly from the copyright holder. To view a copy of this licence, visit http://creativecommons.org/licenses/by/4.0/ The Creative Commons Public Domain Dedication waiver (http://creativecommons.org/publicdomain/zero/1.0/) applies to the data made available in this article, unless otherwise stated in a credit line to the data. 
SGLT2i can inhibit inflammation and improve insulin resistance[8], as well as modulate the gut microbiota of type 2 diabetes mice[9]. For nondiabetic mice, SGLT2i may play an antioxidant and antiinflammatory role [10]. Some studies reported that their cardioprotective role could be associated with reduced arterial stiffness [11], improved myocardial metabolism [12] and increased antioxidative capacity [13]. Ken et al. systematically reviewed preclinical data on the cardioprotective effects of SGLT2i and found that a reduction in atherosclerosis was one of the underlying mechanisms [14].

Atherosclerosis is a systemic pathological process, accompanying fat deposition and chronic inflammation within the artery wall. Atherosclerosis is the leading cause of the majority of clinical cardiovascular events, such as myocardial infarction and stroke [15]. Many risk factors contributed to the initiation and progression of atherosclerosis. Overactivation of the sympathetic system accelerated atherosclerosis while renal denervation mitigated atherosclerosis [16, 17]. Renin-angiotensinaldosterone system (RAAS) mainly acted on vessels, and promoted the development of hypertension, insulin resistance, vascular and systemic inflammation [18].And RAAS inhibitors have been widely used in atherosclerosis prevention [19]. Previous studies found that SGLT2i could mitigate atherosclerosis by reducing weight and fat, as well as the infiltration of inflammatory cells in plaque [20]. Besides, SGLT2i reduced atherosclerosis by enhancing lipoprotein clearance or decreasing resident macrophages in type 1 diabetic mice $[21,22]$. It is well to known that SGLT2i could alleviate the atherosclerosis in diabetic patients. However, the potential role and mechanisms of SGLT2i in atherosclerosis without diabetes are not fully understood.

Therefore, it is hypothesized that empagliflozin, as a kind of SGLT2i, can inhibit the progression of atherosclerosis in a non-diabetic model by virtue of lipid lowering, regulation of sympathetic activity and RAAS.

\section{Materials and Methods}

\section{Animals}

ApoE-/- male mice (6-8 weeks old, Institute of Model Animals of Nanjing University, Nanjing, China) were kept in a temperature-controlled room (a constant temperature of $23^{\circ} \mathrm{C}$ with a humidity of 55-60\%) with a 12-hour light-dark cycle. After 1 week of adaptation to the housing environment, the mice were randomly divided into three groups: sham group, AS group, and EMPA group. The AS group is ApoE-/- mice fed a Western diet containing $0.2 \%$ (wt/wt) cholesterol and $42 \%$ fat (\#TP26303, TROPHIC Animal Feed High Tech Co., Ltd, Nantong, China) for 12 weeks. The EMPA group is also fed on a Western diet and received drinking water containing $10 \mathrm{mg} / \mathrm{kg} / \mathrm{d}$ [23-25] (a higher dose to explore the therapeutic effect on an advanced atherosclerosis model) of empagliflozin (CAS No.: 864070-44-0, MedChemExpress, NJ, USA) beginning at the 7th week. The sham group is ApoE-/- mice fed a chow diet. Each group had 6 mice (Fig. 1A). All mouse studies were approved by the Nanjing University Animal Care and Use Committee. The study was approved by the Ethics Review Board of Nanjing Drum Tower Hospital (No: 2019AE01062).

\section{Atherosclerotic lesion analysis}

After 12 weeks, mice were euthanized with an inhalation overdose of isoflurane and subjected to cervical dislocation. The entire aorta was harvested and observed under a stereomicroscope, and fixed in $4 \%$ paraformaldehyde overnight. Then, the aorta was opened longitudinally and stained in Oil Red O solution (Sevicebio, Wuhan, China) for 2 hours at room temperature. Images were captured using a high-resolution camera. For plaque area analysis in the aortic sinus, the upper portion of the heart above the line connecting the left and right auricles and proximal aorta was fixed and embedded in paraffin. Slides $(10 \mu \mathrm{m})$ were cut and stained with hematoxylin-eosin or Movat (Sevicebio, Wuhan, China). Images were captured using an Olympus microscope. Lesion size was semi-measured with Image software (NIH, Bethesda, USA), which was not so objective.

\section{ELISA}

Mouse serum was collected at the end of the 12 weeks. The lipid profile [total cholesterol (TC), triglycerides (TG), low-density lipoprotein-c (LDL-C) and highdensity lipoprotein-c (HDL-C)], inflammatory cytokines (IL-1 $\beta$, IL-6 and IL-10), RAAS mediators (renin, angiotensin II and aldosterone) and sympathetic mediators (norepinephrine and neuropeptide Y) were measured by ELISA (Jin Yibai Biological Technology Co., Ltd., Nanjing, China) according to the manufacturer's instructions using a standard curve $(n=6)$. The sensitivities for these indexes were $0.16 \mathrm{mmol} / \mathrm{L}$ (TC), $0.32 \mathrm{mmol} / \mathrm{L}$ (TG), 0.2 $\mathrm{mmol} / \mathrm{L}$ (LDL-C), $0.2 \mathrm{mmol} / \mathrm{L}$ (HDL-C), $5 \mathrm{ng} / \mathrm{L}$ (IL-1 $\beta$ ), $5 \mathrm{pg} / \mathrm{mL}$ (IL-6), $30 \mathrm{pg} / \mathrm{mL}$ (IL-10), $5 \mathrm{ng} / \mathrm{L}$ (renin), $20 \mathrm{ng} /$ $\mathrm{L}$ (AngII), $5 \mathrm{ng} / \mathrm{L}$ (ALD), $5 \mathrm{ng} / \mathrm{L}$ (NE), and $4.5 \mathrm{ng} / \mathrm{L}$ (NPY). The optical densities of the samples were detected using a microplate reader (BIOTEK, Vermont, USA) at a wavelength of $450 \mathrm{~nm}$. All results were shown in Table 1.

\section{Statistical analysis}

Data are presented as the mean \pm standard deviation. One-way analysis of variance with the Bonferroni post hoc test was used for multiple comparisons. For non- 


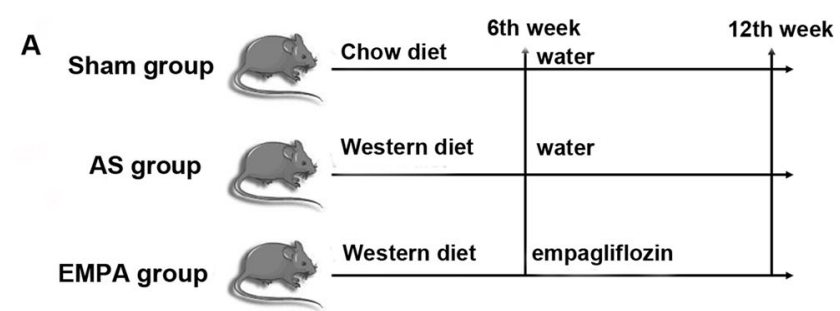

B
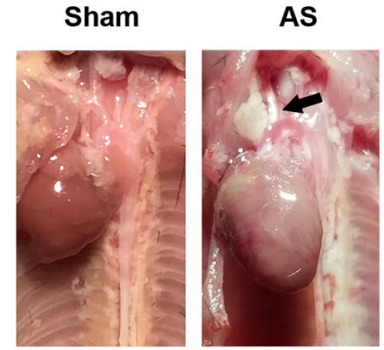

EMPA

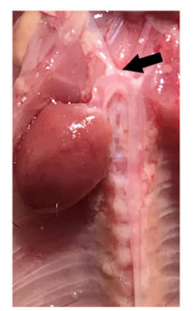

E

Sham

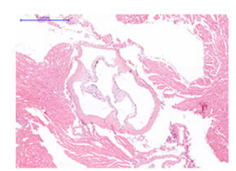

F

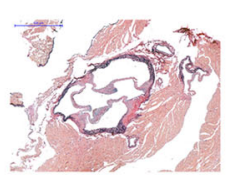

AS
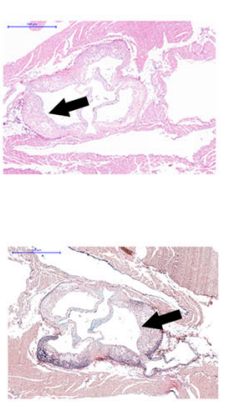

C

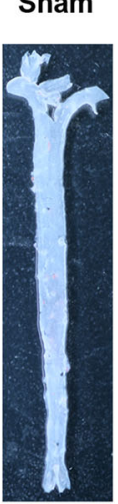

AS

EMPA
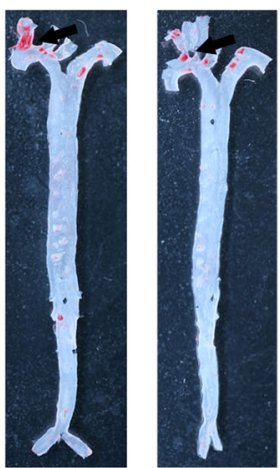

D
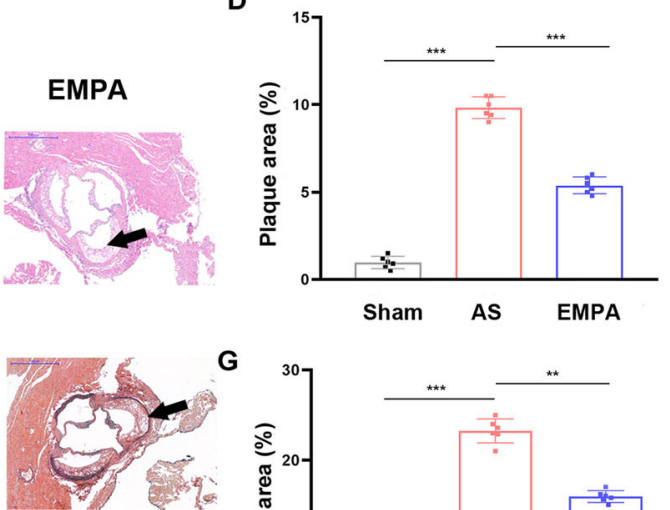

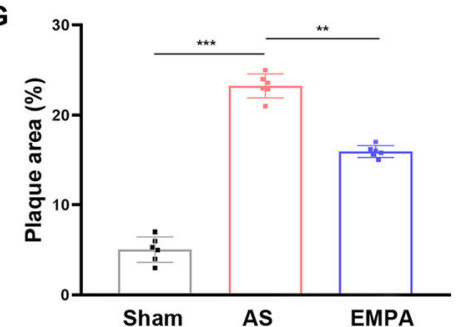

Fig. 1 Empagliflozin attenuated the atherosclerotic lesion area. Schematic protocol for mice treatments (a). Representative macroscopic image (b), En face Oil Red O staining (c) and quantitative results (d), HE staining (e), Movat staining (f) and quantitative results $(\mathbf{g}) . n=6,{ }^{* *} P<0.01,{ }^{* * *} P<$ 0.001. AS, atherosclerosis group; EMPA, empagliflozin group. One-way analysis of variance with the Bonferroni post hoc test was used. The black arrow indicated the atherosclerotic lesion on aortic arch in $\mathbf{b} \& \mathbf{c}$, and on aortic root in $\mathbf{e} \& \mathbf{f}$

parametric variables, Kruskal-Wallis test was used. $\mathrm{P}<$ 0.05 was considered statistically significant. All statistical analyses were performed using Prism 8 (GraphPad Software, San Diego, USA).

\section{Results}

The SGLT2i attenuates atherosclerotic lesion area

To assess the therapeutic role of SGLT2i in atherosclerosis in mice, ApoE-/- mice were fed a Western diet for 12 weeks (AS group), while the EMPA group received empagliflozin at a dose of $10 \mathrm{mg} / \mathrm{kg} /$ day from the 7 th to the 12 th week. The experimental protocol was shown in Fig. 1A. Macroscopically, the atherosclerotic lesion size in the aortic arch was decreased in the EMPA group compared with the AS group (Fig. 1B). En face Oil Red $\mathrm{O}$ staining also confirmed the presence of a reduced atherosclerotic lesion area within the aortic arch in the EMPA group (Fig. $1 \mathrm{C}$ and D). According to the HE and Movat staining analysis (Fig. 1E, F and G), empagliflozin significantly 
Table 1 The results of ELISA between Sham, AS and EMPA group

\begin{tabular}{|c|c|c|c|c|}
\hline & Sham group, $n=6$ & AS group, $n=6$ & EMPA group, $n=6$ & $P$ value \\
\hline TG & $1.56 \pm 0.35$ & $4.45 \pm 1.18^{\# \# \#}$ & $2.05 \pm 0.58^{* * *}$ & $<0.0001$ \\
\hline TC & $33.37 \pm 11.27$ & $68.66 \pm 7.94^{\# \#}$ & $53.38 \pm 4.28^{*}$ & $<0.0001$ \\
\hline $\mathrm{HDL}$ & $5.31 \pm 1.83$ & $8.57 \pm 2.32^{\#}$ & $6.49 \pm 1.58$ & 0.0549 \\
\hline LDL & $6.97 \pm 1.67$ & $15.10 \pm 2.05^{\# \#}$ & $12.16 \pm 0.69^{*}$ & $<0.0001$ \\
\hline $\mid L-1 \beta$ & $60.72 \pm 1.70$ & $60.95 \pm 2.92$ & $59.32 \pm 3.64$ & 0.6401 \\
\hline IL-6 & $72.48 \pm 1.81$ & $83.22 \pm 5.79$ & $82.47 \pm 8.95$ & 0.0327 \\
\hline IL-10 & $335.2 \pm 24.0$ & $426.2 \pm 34.63^{\#}$ & $392.3 \pm 27.06^{*}$ & 0.0026 \\
\hline Renin & $143.4 \pm 8.72$ & $156.8 \pm 6.24^{\# \#}$ & $147.5 \pm 3.81^{*}$ & 0.0208 \\
\hline Ang $\|$ & $269.6 \pm 33.53$ & $287.3 \pm 11.96$ & $305.5 \pm 9.38$ & 0.0692 \\
\hline ALD & $115.8 \pm 2.92$ & $127.9 \pm 6.20^{\# \#}$ & $111.2 \pm 4.23^{* * *}$ & 0.0003 \\
\hline NE & $73.77 \pm 5.38$ & $86.87 \pm 4.29^{\# \#}$ & $77.94 \pm 3.07^{*}$ & 0.0045 \\
\hline NPY & $91.82 \pm 1.98$ & $98.54 \pm 2.62^{\# \#}$ & $89.72 \pm 3.93^{* *}$ & 0.0026 \\
\hline
\end{tabular}

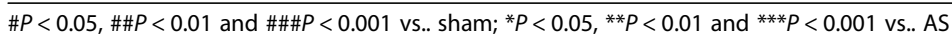

reduced the lesion size at the cross section of aortic $\operatorname{root}(-8.6 \%, P=0.004)$.

The SGLT2i decreases lipid levels in atherosclerosis Excess lipid deposits contributed to the initiation of atherosclerosis and plaque vulnerability. Therefore, the effect of empagliflozin on lipid profiles of atherosclerotic mice was evaluated. The ELISA results showed that empagliflozin could decrease the levels of triglyceride $(2.05 \pm 0.58$ in the EMPA group vs.. $4.45 \pm 1.18 \mathrm{mmol} / \mathrm{l}$ in the AS group, $P<0.001$; Fig. $2 \mathrm{~A})$, total cholesterol $(53.4 \pm 4.28$ vs. $68.7 \pm 7.94$ $\mathrm{mmol} / \mathrm{l}, P<0.05$; Fig. $2 \mathrm{~B})$, and LDL $(12.1 \pm 0.69$ vs.. $15.1 \pm 2.05 \mathrm{mmol} / \mathrm{l}, P<0.05$; Fig. $2 \mathrm{C}$ ). However, HDL was not significantly different between groups (Fig. 2D).

\section{A}
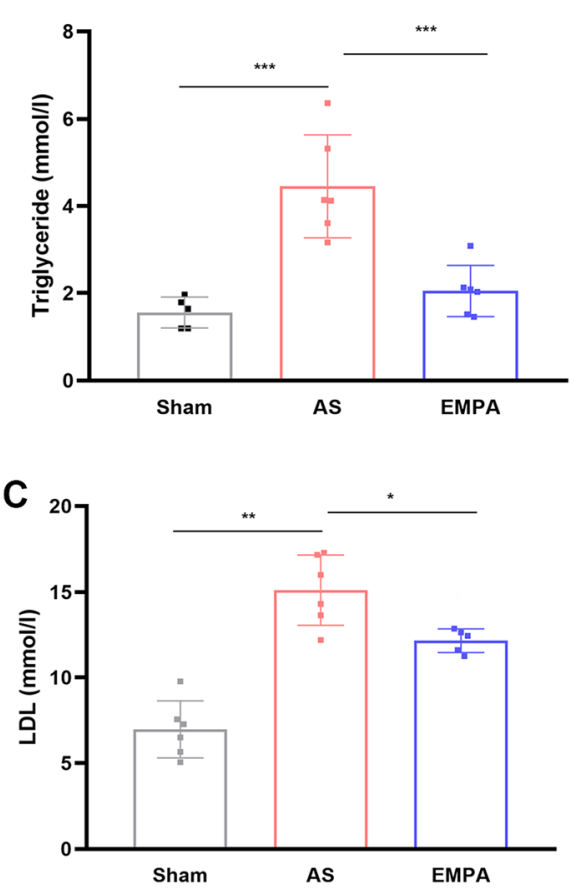

B
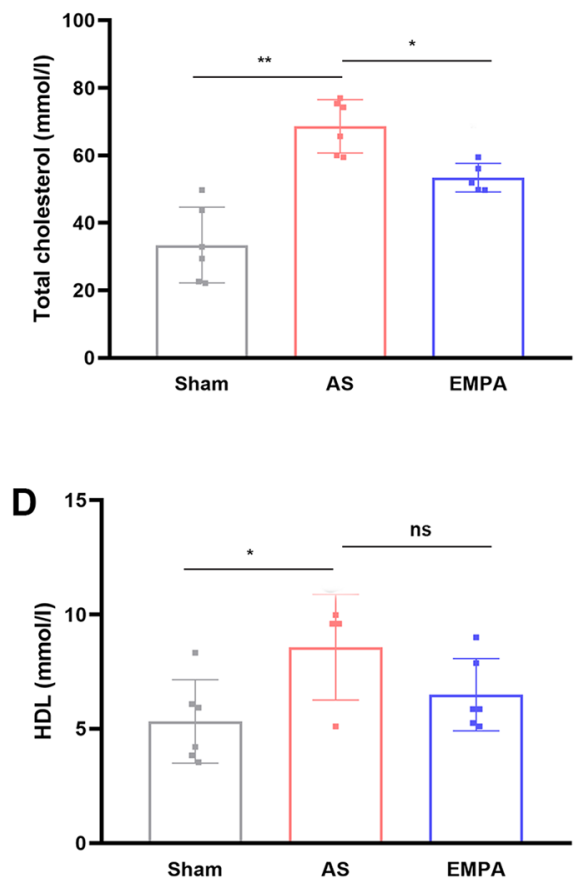

Fig. 2 The serum levels of triglycerides (a), total cholesterol (b), LDL (c) and HDL (d) in the sham, AS and EMPA groups. AS, atherosclerosis group; EMPA, empagliflozin group. One-way analysis of variance with the Bonferroni post hoc test was used. $n=6,{ }^{*} P<0.05,{ }^{* *} P<0.01,{ }^{* * *} P<0.001$ 
The SGLT2i minimally alleviates systemic inflammation in atherosclerosis

Chronic inflammation is also an important trigger of atherosclerosis initiation and development. The results found that IL-1 $\beta$ (Fig. 3A) and IL-6 (Fig. 3B) were not significantly decreased in the EMPA group, except for IL-10 $(392.3 \pm 27.06 \mathrm{pg} / \mathrm{ml}$ in the EMPA group vs.. $426.2 \pm 34.63 \mathrm{pg} / \mathrm{ml}$ in the AS group, $P<0.05$; Fig. $3 C$ ). These results suggested that empagliflozin may have a minimal anti-inflammatory role.

The SGLT2i inhibits the renin-angiotensin-aldosterone system (RAAS) and sympathetic activity

Chronic activation of the renin-angiotensin-aldosterone system (RAAS) contributes to vascular remodeling. The results showed that renin (Fig. 4A) and aldosterone (Fig. 4C) were increased in the AS group. While empagliflozin partially inhibited the levels of renin (147.5 \pm 3.81 in the EMPA group vs.. $156.8 \pm 6.24 \mathrm{ng} / \mathrm{l}$ in the AS group, $P<0.05)$ and aldosterone $(111.2 \pm 4.23$ vs.. $127.9 \pm 6.20 \mathrm{ng} / \mathrm{l}, \quad P<0.001)$. While angiotensin II (Fig. 4B) didn't show a statistical difference among groups. This result indicated that empagliflozin could alleviate the activation of the RAAS. In addition to RAAS, sympathetic activation also speeds up the progression of atherosclerosis. The results showed that norepinephrine $(77.9 \pm 3.07 \mathrm{ng} / \mathrm{l}$ in the EMPA group vs.. $86.9 \pm 4.29 \mathrm{ng} / \mathrm{l}$ in the AS group, $P<0.05$; Fig. $5 \mathrm{~A}$ ) and neuropeptide $\mathrm{Y}$ $(89.7 \pm 3.93$ vs. $98.5 \pm 2.62 \mathrm{ng} / \mathrm{l}, P<0.01$; Fig. $5 \mathrm{~B})$ were partially inhibited after empagliflozin treatment. Interestingly, empagliflozin also decreased the body weight (Fig. 5C) of AS mice $(-3.27 \mathrm{~g}, P=0.002)$. Considering that SGLT2i could regulate the differentiation of epicardial adipose tissue and perivascular adipose tissue, as well as improve insulin resistance and fat distribution [26]. Therefore, empagliflozin may decrease fat mass induced by a high-fat diet $[27,28]$.

\section{Discussion}

It is widely acknowledged that ApoE mice fed a high-fat diet can be used to establish an advanced atherosclerosis model [29-32]. The study showed that empagliflozin could reduce atherosclerotic plaques in ApoE-/- mice. At the same time, group of animals actively treated by EMPA was reported with decreased body weight, improved lipid profiles, and reduced RAAS and sympathetic activity, but not with the significant antiinflammatory effect.

Excessive lipid deposition promotes the development of atherosclerosis. However, the effect of SGLT2i on lipid profiles is not consistent in animal studies. Several
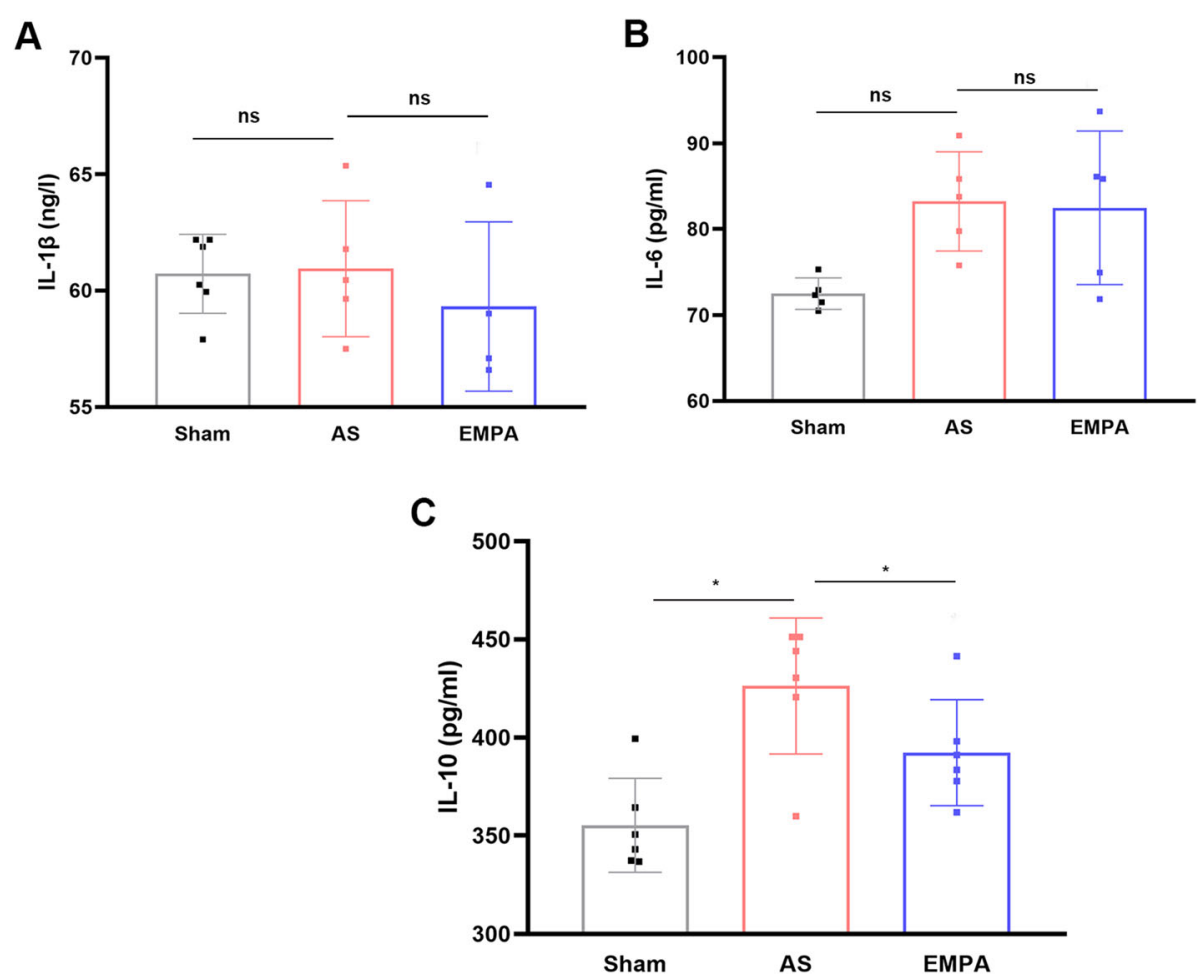

Fig. 3 The serum levels of IL-1B (A), IL-6 (B), and IL-10 (C) in the sham, AS and EMPA groups. AS, atherosclerosis group; EMPA, empagliflozin group. One-way analysis of variance with the Bonferroni post hoc test was used. $n=6$, ${ }^{*} P<0.05$, ns, not significant 

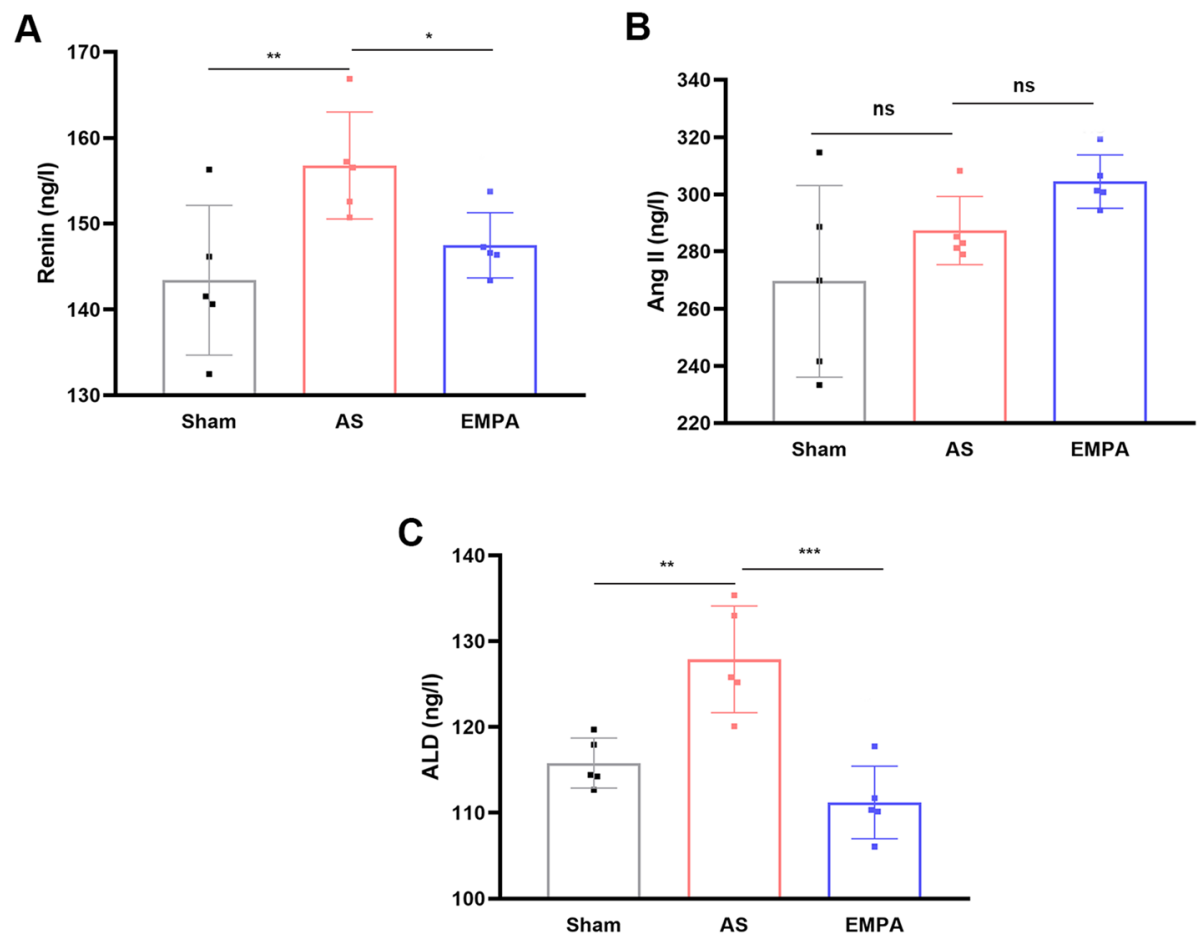

Fig. 4 The serum levels of renin (a), angiotensin II (b) and aldosterone (c) between groups. AS, atherosclerosis group; EMPA, empagliflozin group. One-way analysis of variance with the Bonferroni post hoc test was used. $n=6,{ }^{*} P<0.05,{ }^{* *} P<0.01,{ }^{* * *} P<0.001$, ns, not significant

A

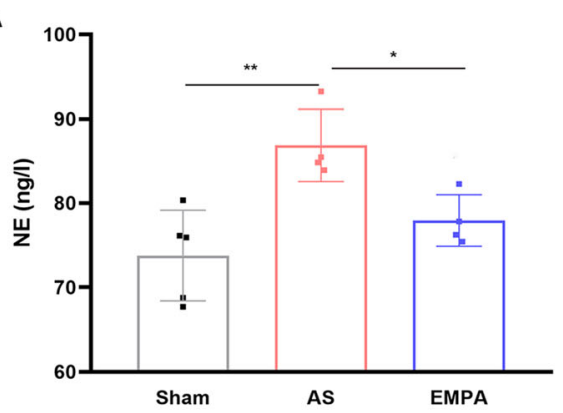

B

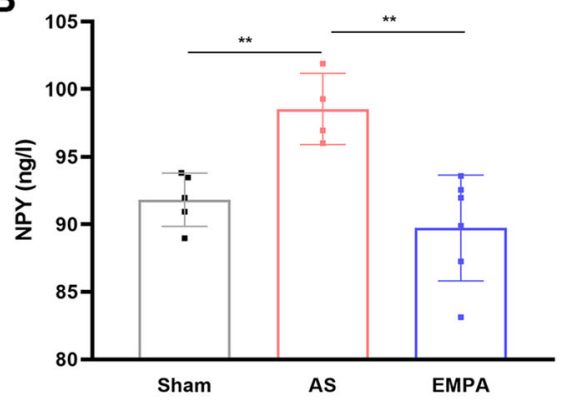

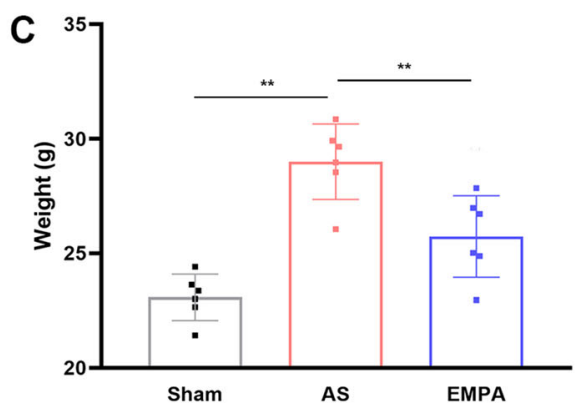

Fig. 5 The serum levels of norepinephrine (a) and neuropeptide $Y(\mathbf{b})$ and body weight (c) in the sham, AS and EMPA groups. AS, atherosclerosis group; EMPA, empagliflozin group. One-way analysis of variance with the Bonferroni post hoc test was used. $n=6,{ }^{*} P<0.05,{ }^{* *} P<0.01$ 
previous studies have shown that SGLT2i can lower lipid levels [21,33-35], while others have not [36-40]. The results showed that empagliflozin could reduce the levels of TC, TG and LDL-C, while there was no significant difference in HDL-C between the two groups. SGLT2i may decrease lipid uptake and metabolism by modulating related genes, such as Mrs1, Scarb1, Cd36, Olr1 or Abca1 [29]. However, further studies are needed to fully elucidate the mechanism of SGLT2i on lipid profiles.

Empagliflozin significantly reduced the expression of norepinephrine and neuropeptide $\mathrm{Y}$, as well as renin, and aldosterone. However, angiotensin II was not statistically changed by empagliflozin treatment, which could be supplemented from other sources. The urine Ang II and angiotensinogen levels should be measured instead from the previous study [41]. As an antidiabetic drug, SGLT2i has been confirmed to decrease the risk of cardiovascular death or hospitalization for heart failure, regardless of the presence or absence of diabetes [42]. Previous studies have also demonstrated that SGLT2i reduces the development of atherosclerotic lesions in diabetic and nondiabetic mice $[21,22,43,44]$. In accordance with previous results, the study confirmed that lipid-lowering and inhibition of sympathetic activity and RAAS contributed to the antiatherogenic effects of empagliflozin.

In addition to lipid deposition and overaction of sympathetic system and RAAS, extensive observations supported the importance of inflammation in atherosclerosis [45]. Some inflammatory cells and mediators promoted the development of atherosclerosis through activating both innate and adaptive immune pathways [46]. Bedsides, a few anti-inflammatory treatments have reduced the risk of atherosclerotic heart disease [47]. However, the systemic inflammation level of atherosclerosis in the SGLT2i group was not significantly different. Two factors can explain this difference: on the one hand, the nondiabetic ApoE-/- mice may not have a significant vascular inflammatory response induced by hyperglycemia. Nakatsu et al. demonstrated that hyperglycemia rapidly induced a vascular inflammatory response, which can be normalized by short-term (7 days) treatment with the SGLT2i luseogliflozin [37]. A previous study confirmed that empagliflozin did not lead to a significant difference in glucose levels in nondiabetic states [48]. On the other hand, the systemic inflammation level is likely affected by the duration of treatment with SGLT2i. The duration in the experiment was 12 weeks, and the experimental group was treated with SGLT2i beginning at the 7th week. Combining previous studies, SGLT2i may inhibit inflammatory mediators with a duration of at least 8 weeks $[8,9,44,49]$. Therefore, short-term empagliflozin treatment may not be enough to have an anti-inflammatory effect.
In recent years, some mechanisms underlying the beneficial effect of SGLT2i on atherosclerosis have been proposed. In diabetic states, SGLT2 inhibitions might enhance glycemic control and lipoprotein clearance [21] while lowering sympathetic activation [50]. The decreased toxicity of glucose to endothelial cells may be a potential mechanism involved in the prevention of atherosclerosis in diabetic ApoE-/- mice [49]. While in non-diabetic conditions, SGLT2 inhibitors could increase adiponectin levels and reduce fat deposition [20]. Besides, Tracey et al. found SGLT2 inhibitors attenuated human vascular endothelial cell activation and induced vasorelaxation to inhibit atherogenesis [51]. In addition, SGLT2i could enhance lipoprotein clearance through heparan sulfate proteoglycans (HSPGs) and bile acid pathways [21], which could protect against atherosclerosis progression. Besides, vWF, involved in platelet adhesion and aggregation, could be a target of SGT2i [52], however, it needs further experiment validation.

\section{Study strength and limitations}

Overall, SGLT2i had a beneficial effect on the progression of atherosclerosis, partially explaining its cardioprotective effect. Due to a relatively short-term treatment, there may be no significant difference in some experimental results. Future long-term empagliflozin treatment studies should be performed. Besides, this study was only an unregistered animal experiment, and further clinical trials should be conducted for its application in atherosclerosis.

\section{Conclusions}

In summary, the SGLT2i, empagliflozin, may exert a protective role in atherosclerosis by reducing lipid levels and inhibiting sympathetic and RAAS activity. This study had laid a foundation that SGLT2i could be applied for the prevention and treatment of atherosclerosis in the clinical practice.

\section{Abbreviations \\ SGLT2i: Sodium-glucose cotransporter 2 inhibitors; RAAS: Renin-angiotensin- aldosterone system; ACS: Acute coronary syndrome; TC: Total cholesterol; TG: Triglycerides; LDL-C: Low-density lipoprotein-C; HDL-C: High-density lipoprotein-c; HSPG: Heparan sulfate proteoglycans}

\section{Acknowledgements \\ None.}

\section{Authors' contributions}

$K L N$ and $X B$ designed this study; $L Y H$ and $X J M$ wrote the manuscript; $W$ MY performed the experiments. The authors read and approved the final manuscript.

\section{Funding}

This research was supported by the National Natural Science Foundation of China ( 81700389) 


\section{Availability of data and materials}

The data are available upon request.

\section{Ethics approval and consent to participate}

The study was approved by the Ethics Review Board of Nanjing Drum Tower Hospital (No: 2019AE01062).

\section{Consent for publication}

Yes.

\section{Competing interests}

None.

\section{Author details}

'Department of Cardiology, Nanjing Drum Tower Hospital, Clinical College of Nanjing Medical University, Jiangsu 210008 Nanjing, China. ${ }^{2}$ Department of Cardiology, Affiliated Drum Tower Hospital, Nanjing University Medical School, 210008 Nanjing, Jiangsu, China.

\section{Received: 26 October 2020 Accepted: 4 January 2021}

Published online: 12 January 2021

\section{References}

1. Kanai Y, Lee WS, You G, Brown D, Hediger MA. The human kidney low affinity Nat/glucose cotransporter SGLT2. Delineation of the major renal reabsorptive mechanism for D-glucose. J Clin Invest. 1994;93:397-404.

2. Monica Reddy RP, Inzucchi SE. SGLT2 inhibitors in the management of type 2 diabetes. Endocrine. 2016:53:364-72.

3. Abdul-Ghani MA, Norton L, Defronzo RA. Role of sodium-glucose cotransporter 2 (SGLT 2) inhibitors in the treatment of type 2 diabetes. Endocr Rev. 2011:32:515-31.

4. Zinman B, Wanner C, Lachin JM, Fitchett D, Bluhmki E, Hantel S, Mattheus M, Devins T, Johansen OE, Woerle $\mathrm{HJ}$, et al. Empagliflozin, cardiovascular outcomes, and mortality in Type 2 diabetes. N Engl J Med. 2015;373:211728

5. Neal B, Perkovic V, Mahaffey KW, de Zeeuw D, Fulcher G, Erondu N, Shaw W, Law G, Desai M, Matthews DR, Group CPC. Canagliflozin and cardiovascular and renal events in Type 2 diabetes. N Engl J Med. 2017;377: 644-57.

6. Wiviott SD, Raz I, Bonaca MP, Mosenzon O, Kato ET, Cahn A, Silverman MG Zelniker TA, Kuder JF, Murphy SA, et al. Dapagliflozin and cardiovascular outcomes in type 2 diabetes. N Engl J Med. 2019;380:347-57.

7. Dziuba J, Alperin P, Racketa J, Iloeje U, Goswami D, Hardy E, Perlstein I, Grossman HL, Cohen M. Modeling effects of SGLT-2 inhibitor dapagliflozin treatment versus standard diabetes therapy on cardiovascular and microvascular outcomes. Diabetes Obes Metab. 2014;16:628-35.

8. Leng W, Ouyang X, Lei X, Wu M, Chen L, Wu Q, Deng W, Liang Z. The SGLT2 Inhibitor dapagliflozin has a therapeutic effect on atherosclerosis in diabetic ApoE(-/-) mice. Mediators Inflamm. 2016;2016:6305735.

9. Lee DM, Battson ML, Jarrell DK, Hou S, Ecton KE, Weir TL, Gentile CL. SGLT2 inhibition via dapagliflozin improves generalized vascular dysfunction and alters the gut microbiota in type 2 diabetic mice. Cardiovasc Diabetol. 2018 17:62.

10. Andreadou I, Efentakis P, Balafas E, Togliatto G, Davos $\mathrm{CH}$, Varela A, Dimitriou CA, Nikolaou PE, Maratou E, Lambadiari V, et al. Empagliflozin limits myocardial infarction in vivo and cell death in vitro: role of STAT3, mitochondria, and redox aspects. Front Physiol. 2017;8:1077.

11. Ooi H, Chung W, Biolo A. Arterial stiffness and vascular load in heart failure Congest Heart Fail. 2008:14:31-6.

12. Garcia-Ropero A, Santos-Gallego CG, Zafar MU, Badimon JJ. Metabolism of the failing heart and the impact of SGLT2 inhibitors. Expert Opin Drug Metab Toxicol. 2019;15:275-85.

13. Oshima H, Miki T, Kuno A, Mizuno M, Sato T, Tanno M, Yano T, Nakata K, Kimura $Y$, Abe $K$, et al. Empagliflozin, an SGLT2 inhibitor, reduced the mortality rate after acute myocardial infarction with modification of cardiac metabolomes and antioxidants in diabetic rats. J Pharmacol Exp Ther. 2019; 368:524-34

14. Chin KL, Ofori-Asenso R, Hopper I, von Lueder TG, Reid CM, Zoungas S, Wang $\mathrm{BH}$, Liew D. Potential mechanisms underlying the cardiovascular benefits of sodium glucose cotransporter 2 inhibitors: a systematic review of data from preclinical studies. Cardiovasc Res. 2019;115:266-76.
15. Benjamin EJ, Blaha MJ, Chiuve SE, Cushman M, Das SR, Deo R, de Ferranti SD, Floyd J, Fornage M, Gillespie C, et al. Heart disease and stroke statistics2017 update: a report from the American Heart Association. Circulation. 2017;135:e146-603

16. Al-Sharea A, Lee MKS, Whillas A, Michell DL, Shihata WA, Nicholls AJ, Cooney OD, Kraakman MJ, Veiga CB, Jefferis AM, et al. Chronic sympathetic driven hypertension promotes atherosclerosis by enhancing hematopoiesis. Haematologica. 2019;104:456-67.

17. Chen H, Wang R, Xu F, Zang T, Ji M, Yin J, Chen J, Shen L, Ge J. Renal denervation mitigates atherosclerosis in ApoE-/- mice via the suppression of inflammation. Am J Transl Res. 2020;12:5362-80.

18. Durante A, Peretto G, Laricchia A, Ancona F, Spartera M, Mangieri A, Cianflone D. Role of the renin-angiotensin-aldosterone system in the pathogenesis of atherosclerosis. Curr Pharm Des. 2012;18:981-1004.

19. Patarroyo Aponte MM, Francis GS. Effect of Angiotensin-converting enzyme inhibitors and Angiotensin receptor antagonists in atherosclerosis prevention. Curr Cardiol Rep. 2012;14:433-42.

20. Han JH, Oh TJ, Lee G, Maeng HJ, Lee DH, Kim KM, Choi SH, Jang HC, Lee HS, Park KS, et al. The beneficial effects of empagliflozin, an SGLT2 inhibitor, on atherosclerosis in ApoE (-/-) mice fed a western diet. Diabetologia. 2017; 60:364-76.

21. Al-Sharea A, Murphy AJ, Huggins LA, Hu Y, Goldberg IJ, Nagareddy PR. SGLT2 inhibition reduces atherosclerosis by enhancing lipoprotein clearance in Ldlr(-/-) type 1 diabetic mice. Atherosclerosis. 2018;271:166-76.

22. Pennig J, Scherrer P, Gissler MC, Anto-Michel N, Hoppe N, Funer L, Hardtner C, Stachon P, Wolf D, Hilgendorf I, et al. Glucose lowering by SGLT2inhibitor empagliflozin accelerates atherosclerosis regression in hyperglycemic STZ-diabetic mice. Sci Rep. 2019;9:17937.

23. Byrne NJ, Matsumura N, Maayah ZH, Ferdaoussi M, Takahara S, Darwesh AM, Levasseur JL, Jahng JWS, Vos D, Parajuli N, et al. Empagliflozin blunts worsening cardiac dysfunction associated with reduced NLRP3 (nucleotidebinding domain-like receptor protein 3) inflammasome activation in heart failure. Circ Heart Fail. 2020;13:e006277.

24. Xue M, Li T, Wang Y, Chang Y, Cheng Y, Lu Y, Liu X, Xu L, Li X, Yu X, et al. Empagliflozin prevents cardiomyopathy via sGC-cGMP-PKG pathway in type 2 diabetes mice. Clin Sci (Lond). 2019;133:1705-20.

25. Li C, Zhang J, Xue M, Li X, Han F, Liu X, Xu L, Lu Y, Cheng Y, Li T, et al. SGLT2 inhibition with empagliflozin attenuates myocardial oxidative stress and fibrosis in diabetic mice heart. Cardiovasc Diabetol. 2019;18:15.

26. Neeland IJ, McGuire DK, Chilton R, Crowe S, Lund SS, Woerle HJ, Broedl UC, Johansen OE. Empagliflozin reduces body weight and indices of adipose distribution in patients with type 2 diabetes mellitus. Diab Vasc Dis Res. 2016;13:119-26

27. Kakuda H, Kobayashi J, Sakurai M, Takekoshi N. Residual effect of sodium glucose cotransporter 2 inhibitor, tofogliflozin, on body weight after washout in Japanese men with type 2 diabetes. J Clin Med Res. 2019;11:35-41.

28. Ohta A, Kato H, Ishii S, Sasaki Y, Nakamura Y, Nakagawa T, Nagai Y, Tanaka Y. Ipragliflozin, a sodium glucose co-transporter 2 inhibitor, reduces intrahepatic lipid content and abdominal visceral fat volume in patients with type 2 diabetes. Expert Opin Pharmacother. 2017;18:1433-8.

29. Zhang Q, Hu J, Wu Y, Luo H, Meng W, Xiao B, Xiao X, Zhou Z, Liu F. Rheb (Ras Homolog Enriched in Brain 1) deficiency in mature macrophages prevents atherosclerosis by repressing macrophage proliferation, inflammation, and lipid uptake. Arterioscler Thromb Vasc Biol. 2019:39:1787-801.

30. Finney AC, Funk SD, Green JM, Yurdagul A Jr, Rana MA, Pistorius R, Henry M, Yurochko A, Pattillo CB, Traylor JG, et al. EphA2 expression regulates inflammation and fibroproliferative remodeling in atherosclerosis. Circulation. 2017;136:566-82.

31. Zysset D, Weber B, Rihs S, Brasseit J, Freigang S, Riether C, Banz Y, Cerwenka A Simillion C, Marques-Vidal P, et al. TREM-1 links dyslipidemia to inflammation and lipid deposition in atherosclerosis. Nat Commun. 2016;7:13151.

32. Knight JS, Luo W, O'Dell AA, Yalavarthi S, Zhao W, Subramanian V, Guo C, Grenn RC, Thompson PR, Eitzman DT, Kaplan MJ. Peptidylarginine deiminase inhibition reduces vascular damage and modulates innate immune responses in murine models of atherosclerosis. Circ Res. 2014;114: 947-56.

33. Dimitriadis GK, Nasiri-Ansari N, Agrogiannis G, Kostakis ID, Randeva MS, Nikiteas N, Patel VH, Kaltsas G, Papavassiliou AG, Randeva HS, Kassi E. 
Empagliflozin improves primary haemodynamic parameters and attenuates the development of atherosclerosis in high fat diet fed APOE knockout mice. Mol Cell Endocrinol. 2019;494:110487.

34. Nasiri-Ansari N, Dimitriadis GK, Agrogiannis G, Perrea D, Kostakis ID, Kaltsas G, Papavassiliou AG, Randeva HS, Kassi E. Canagliflozin attenuates the progression of atherosclerosis and inflammation process in APOE knockout mice. Cardiovasc Diabetol. 2018;17:106.

35. Gragnano F, Calabro P. Role of dual lipid-lowering therapy in coronary atherosclerosis regression: Evidence from recent studies. Atherosclerosis. 2018;269:219-28

36. Basu D, Huggins LA, Scerbo D, Obunike J, Mullick AE, Rothenberg PL, Di Prospero NA, Eckel RH, Goldberg IJ. Mechanism of increased LDL (Low-Density Lipoprotein) and decreased triglycerides with SGLT2 (Sodium-Glucose Cotransporter 2) inhibition. Arterioscler Thromb Vasc Biol. 2018;38:2207-16.

37. Nakatsu Y, Kokubo H, Bumdelger B, Yoshizumi M, Yamamotoya T, Matsunaga Y, Ueda K, Inoue Y, Inoue MK, Fujishiro M, et al. The SGLT2 inhibitor luseogliflozin rapidly normalizes aortic mRNA levels of inflammation-related but not lipid-metabolism-related genes and suppresses atherosclerosis in diabetic ApoE KO mice. Int J Mol Sci. 2017;18:1704

38. Terasaki M, Hiromura M, Mori Y, Kohashi K, Nagashima M, Kushima H, Watanabe T, Hirano T. Amelioration of hyperglycemia with a sodiumglucose cotransporter 2 inhibitor prevents macrophage-driven atherosclerosis through macrophage foam cell formation suppression in type 1 and type 2 diabetic mice. PLoS One. 2015;10:e0143396.

39. Bays HE, Sartipy P, XU J, Sjöström CD, Underberg JA. Dapagliflozin in patients with type II diabetes mellitus, with and without elevated triglyceride and reduced high-density lipoprotein cholesterol levels. J Clin Lipidol. 2017;11:450-8.e451.

40. Abdul-Ghani M, Del Prato S, Chilton R, DeFronzo RA. SGLT2 inhibitors and cardiovascular risk: lessons learned from the EMPA-REG outcome study. Diabetes Care. 2016;39:717-25.

41. Shin SJ, Chung S, Kim SJ, Lee EM, Yoo YH, Kim JW, Ahn YB, Kim ES, Moon SD, Kim MJ, Ko SH. Effect of sodium-glucose co-transporter 2 inhibitor dapagliflozin, on renal renin-angiotensin system in an animal model of type 2 diabetes. PLoS One. 2016;11:e0165703.

42. Packer M, Anker SD, Butler J, Filippatos G, Pocock SJ, Carson P, Januzzi J, Verma S, Tsutsui H, Brueckmann M, et al. Cardiovascular and renal outcomes with empagliflozin in heart failure. N Engl J Med. 2020;383:1413-24.

43. Oelze $M$, Kröller-Schön $S$, Welschof $P$, Jansen $T$, Hausding M, Mikhed $Y$, Stamm P, Mader M, Zinßius E, Agdauletova S, et al. The sodium-glucose cotransporter 2 inhibitor empagliflozin improves diabetes-induced vascular dysfunction in the streptozotocin diabetes rat model by interfering with oxidative stress and glucotoxicity. PLoS One. 2014;9:e112394.

44. Ganbaatar B, Fukuda D, Shinohara M, Yagi S, Kusunose K, Yamada H, Soeki T, Hirata Kl, Sata M. Empagliflozin ameliorates endothelial dysfunction and suppresses atherogenesis in diabetic apolipoprotein E-deficient mice. Eur J Pharmacol. 2020;875:173040.

45. Raggi P, Genest J, Giles JT, Rayner KJ, Dwivedi G, Beanlands RS, Gupta M. Role of inflammation in the pathogenesis of atherosclerosis and therapeutic interventions. Atherosclerosis. 2018;276:98-108.

46. Wolf D, Ley K. Immunity and inflammation in atherosclerosis. Circ Res. 2019; 124:315-27.

47. Shah PK. Inflammation, infection and atherosclerosis. Trends Cardiovasc Med. 2019;29:468-72.

48. Ortega R, Collado A, Selles F, Gonzalez-Navarro H, Sanz MJ, Real JT, Piqueras L. SGLT-2 (Sodium-Glucose Cotransporter 2) inhibition reduces Ang II (Angiotensin II)-induced dissecting abdominal aortic aneurysm in ApoE (Apolipoprotein E) knockout mice. Arterioscler Thromb Vasc Biol. 2019;39:1614-28.

49. Rahadian A, Fukuda D, Salim HM, Yagi S, Kusunose K, Yamada H, Soeki T, Sata M. Canagliflozin prevents diabetes-induced vascular dysfunction in ApoE-deficient mice. J Atheroscler Thromb. 2020;27:1141-51.

50. Elliott RH, Matthews VB, Rudnicka C, Schlaich MP. Is it time to think about the sodium glucose co-transporter 2 sympathetically? Nephrology (Carlton). 2016:21:286-94

51. Gaspari T, Spizzo I, Liu H, Hu Y, Simpson RW, Widdop RE, Dear AE. Dapagliflozin attenuates human vascular endothelial cell activation and induces vasorelaxation: A potential mechanism for inhibition of atherogenesis. Diab Vasc Dis Res. 2018:15:64-73.

52. Gragnano F, Golia E, Natale F, Bianchi R, Pariggiano I, Crisci M, Diana V, Fimiani F, Limongelli G, Russo M, et al. Von Willebrand factor and cardiovascular disease: from a biochemical marker to an attractive therapeutic target. Curr Vasc Pharmacol. 2017;15:404-15.

\section{Publisher's Note}

Springer Nature remains neutral with regard to jurisdictional claims in published maps and institutional affiliations.

\section{Ready to submit your research? Choose BMC and benefit from:}

- fast, convenient online submission

- thorough peer review by experienced researchers in your field

- rapid publication on acceptance

- support for research data, including large and complex data types

- gold Open Access which fosters wider collaboration and increased citations

- maximum visibility for your research: over $100 \mathrm{M}$ website views per year

At BMC, research is always in progress.

Learn more biomedcentral.com/submissions 